\title{
Material educativo sobre prevenção de síndrome pulmonar por hantavírus para crianças indígenas haliti-paresí
}

\section{Educational material on prevention of pulmonary hantavirus syndrome for indigenous children haliti-Paresí}

\author{
${ }^{1}$ Ana Cláudia Pereira Terças-Trettel enfanacnp@gmail.com \\ ${ }^{1}$ Bianca Carvalho da Graça \\ ${ }^{1}$ Ariadne Cristinne Pereira de Moura \\ ${ }^{1}$ Leonir Evandro Zenazokenae \\ ${ }^{1}$ Vagner Ferreira Nascimento \\ 2 Thalise Yuri Hattori \\ 2 Marina Atanaka \\ ${ }^{3}$ Elba Regina Sampaio de Lemos
}

\section{RESUMO}

O estudo tem como objetivo descrever o processo de elaboração de um material educativo sobre a prevenção de hantavirose destinado às crianças indígenas Haliti-Paresí. Foi elaborada cartilha educativa bilíngue, nos idiomas Português (Brasil) e na lingua Aruak, porém nos dialetos Waymarée Kozarini. O material foi destinado para as crianças indígenas Haliti-Paresí com idade inferior a 12 anos. Sua construção correu por meio de reuniões mensais na aldeia Bacaval, entre dezembro de 2014 a julho de 2015, com equipe multiprofissional. Enfatizou-se questões científicas sobre a doença, a fim de promover o aprendizado no qual a criança, de forma participativa e lúdica, (re)conhece o seu cotidiano e estabelece conexões entre exposição e risco e forma de prevenção. Os recursos como narrativas, perguntas, atividades interativas e ilustrações coloridas foram adotados como instrumentos. A elaboração da cartilha permitiu ressignificação do saber científico ao articular as rotinas do cotidiano e as vivencias como forma de percepção de vulnerabilidades e riscos e, até o fortalecimento do uso da língua nativa. Esse entrelaçamento das representações sociais e vivencias mostrou-se como importante estratégia no cuidado e oferta da assistência à saúde de forma mais integral e efetiva.

Palavras-chave: Educação em saúde. Criança. Infecções por hantavírus.

\section{ABSTRACT}

The study aims to describe the process of elaborating educational material on the prevention of hantaviruses for the Haliti-Paresí indigenous children. It was elaborated bilingual educational booklet, in the languages Portuguese (Brazil) and in the language Aruak, but in the dialects Waymaré and Kozarini. The material intend for Haliti-Paresí indigenous children under the age of 12. Its construction carried out through monthly meetings in the village Bacaval, between December 2014 and July 2015, with multiprofessional team. Scientific issues about the disease emphasized in order to promote learning in which the child participatory and playful (re) knows their daily life and establishes connections between exposure and risk and prevention. Resources such as narratives, questions, interactive activities and colorful illustration adopted as tools. The elaboration of the booklet allowed the re-signification of scientific knowledge by articulating daily routines and experiences as a way of perceiving vulnerabilities and risks and even strengthening the use of the native language. This intertwining of social representations and experiences has proven to be an important strategy in the care and offer of health care in a more integral and effective way.

Keywords: Health education. Child. Hantavirus infections.

\footnotetext{
Universidade do Estado de Mato Grosso. UNEMAT - Tangará da Serra-MT

Universidade do Estado de Mato Grosso

Fundação Oswaldo Cruz
} 


\section{INTRODUÇÃO}

A hantavirose se caracteriza por ser uma doença viral, emergente, de caráter agudo e grave, que se manifesta por meio da Febre Hemorrágica com Síndrome Renal (FHSR) no Velho Mundo e da Síndrome Pulmonar por Hantavírus (SPH) nas Américas, ainda que seja possível manifestação clínica que combine ambas as síndromes (LEMOS E SILVA, 2013).

É transmitida ao homem, principalmente pela inalação de inócuos viriais presentes nas excretas de roedores silvestres da família Cricetidae e subfamília Sigmodontinae (MUSSER E CARLETON, 2005;). A gravidade da doença está relacionada com a velocidade com que evolui para a fase cardiopulmonar e óbito, com letalidade de 50\%, impactando diretamente na morbimortalidade das populações que residem em área de risco (VIAL, 2013).

A SPH, está presente em todo continente americano, do Canadá até à região sul da Argentina (BERGER, 2016), e no Brasil está distribuída em quinze estados com 1.988 casos confirmados até junho de 2016, sendo que Mato Grosso é o terceiro estado em número de casos confirmados ( $\mathrm{N}=305)$ e, em expansão para área indígenas (BRASIL, 2016).

Essa zoonose se estabelece, sobretudo, por conta da ocupação humana em áreas localizadas entre os ambientes peridomiciliar e silvestre, ocasionadas por alterações como desmatamento, agricultura, pecuária e/ou afins. Acomete, principalmente populações rurais e populações vulneráveis como os ribeirinhos, quilombolas, garimpeiros, assentados, grileiros e indígenas (NICHIATA et al., 2011).

No perfil de morbimortalidade dos povos indígenas brasileiros, destaca-se o conjunto de doenças infecciosas e parasitárias, no entanto a emergência de novas doenças como a hantavirose se destacam (BASTA et al, 2012). Em Mato Grosso, a doença tem afetado nos últimos anos as comunidades indígenas, habitantes de distintas regiões do estado (TERÇAS et al., 2016b).

Circundada pelos municípios mato-grossenses que mais registraram casos de hantavirose, engloba-se a cidade de Campo Novo do Parecis, que abrange o maior número de casos do país, onde está localizado o Chapadão do Parecis, habitada pela etnia Haliti-Paresí, com território de 1.120.369,5 hectares (TERÇAS et al., 2016b). Uma das nove terras indígenas é a Utiariti, nela residem 327 pessoas em nove aldeias, desses, 118 são crianças menores de 12 anos.

Destaca-se a necessidade de implementação dos cuidados de saúde do povo Haliti-Paresí, com efetiva articulação entre os saberes da medicina tradicional indígena com a medicina ocidental, assim como em quaisquer trabalhos que envolvam povos de culturas diferenciadas.

Uma das estratégias utilizadas para compartilhar conhecimentos em saúde, viabilizar tratamentos e, ao mesmo tempo estimular o autocuidado (FERNANDES et al, 2014) de forma autônoma na prevenção das doenças, estão as atividades didáticas realizadas na comunidade (GOMES et al, 2012) e, a educação em saúde, enquanto um conjunto de saberes e práticas voltados para a prevenção de doenças e promoção da saúde representa um recurso de socialização do conhecimento cientificamente produzido no campo da saúde.

Como instrumentos de intervenção na educação em saúde, foi proposta a cartilha interativa, que atua como um recurso destinado a informar à população acerca de direitos, deveres, acidentes, doenças e afins. Além de facilitar o processo de aprendizado, a cartilha também permite ser lida posteriormente, o que reforça as informações orais, atuando como um guia de orientações para ocasiões de dúvidas podendo ser consultada em diferentes momentos (CASTRO e JÚNIOR, 2014). Os mesmos autores destacam que operacionalmente é necessário a seleção de informações que cumpram a função educativa direta, adequados ao do público-alvo, devendo utilizar-se de abordagem e conteúdo claro, acessível, atrativo, lúdico, dinâmico e com vocabulário coerente, além de propiciar a articulação entre medicina tradicional indígena e a medicina ocidental para assim possibilitar um acesso mais adequado e integral aos indígenas. 
Assim, considerando a relevância destes aspectos, o estudo objetivou descrever o processo de elaboração de um material educativo sobre prevenção de hantavirose às crianças indígenas Haliti-Paresí.

\section{METODOLOGIA}

Trata-se de um estudo baseado no método construtivista na criação de um material educativo, do tipo cartilha. A abordagem construtivista como método de pesquisa permite identificar problemas a partir da realidade local, traçar estratégias para solução do mesmo e construir o conhecimento com os participantes. A produção do conhecimento é resultante da interação entre os envolvidos/participantes de forma dialógica em que os significados, a credibilidade e aceitabilidade são partilhados e consensuados (SIQUEIRA e ERDMANN, 2007).

O estudo foi desenvolvido no As aldeias localizam-se no médio norte mato-grossense e distribuem-se nos municípios de Tangará da Serra, Campo Novo do Parecis, Sapezal, Diamantino, Nova Marilândia, Conquista do Oeste e Barra do Bugres (Figura 1), totalizando 56 e possuindo atualmente, 1.120.369,5 hectares de extensão territorial, com terras em distintas fases de homologação.

Assim, a construção desse material se deu por meio de reuniões mensais na aldeia Bacaval, no período de dezembro de 2014 a julho de 2015, com os membros da equipe, constituída por 13 profissionais, sendo eles médicos, enfermeiros, biólogos e professores indígenas Haliti-Paresí, que seguiram as seguintes etapas: idealização e objetivos, método de comunicação, construção teórica e cultural, revisão e diagramação, teste piloto e divulgação final.

Durante a etapa de idealização e objetivos, foi definido que o público-alvo seriam as crianças indígenas Haliti-Paresí com idade inferior a doze anos, devido à vulnerabilidade de situações vivenciadas em seu cotidiano, identificada em estudo anterior (TERÇAS et al., 2016b).

Posteriormente, na definição do método de comunicação, optou-se pela escolha de cartilha interativa, com caricaturas personalizadas à etnia e ao ambiente que vivem. Dessa forma, além do fornecimento de informações científicas sobre a doença, modos de transmissão e métodos preventivos específicos revestidos às realidades culturais Haliti-Paresí, houve também, a possibilidade da criança interagir dentro dessa dimensão educativa, com exercícios para desenvolvimento de funções psicomotoras, como, pinturas, jogos e questões assertivas.

Na sequência, realizou-se a reunião em forma de oficina, para fundamentação teórica e cultural, isto é, informações sobre o conhecimento da doença e hábitos do cotidiano Haliti-Paresí, esse último, expresso pelos professores indígenas, na perspectiva de estabelecer paralelo entre as medidas de prevenção à realidade cultural dessa etnia e a linguagem a ser utilizada. Definiu-se então, que a cartilha seria bilíngue, grafada em Português (Brasil) e na lingua indígena Aruak, e em dois dialetos o Waymaré e Kozarini, que prevalecem nesta área de estudo.

Na reunião posterior, deu-se a construção do texto e estrutura da cartilha, com discussão entre os pares e, subsequente tradução pelos professores indígenas para a língua Aruak e seus dialetos Waymaré e Kozarini. Nesta etapa, também foram incorporadas fotos do cotidiano das crianças Haliti-Paresí, fornecidas pela comunidade, que juntamente com o texto, foram apresentadas ao caricaturista e diagramador, que elaboraram a arte visual.

Após a construção do primeiro esboço da cartilha, o mesmo foi apresentado a todos os membros da equipe para discussão e avaliação. Subsequentemente, apresentado a cinco crianças Haliti-Paresí em teste piloto, a fim de avaliar a compreensão, as potencialidades e fragilidades do material. Procedeu-se então, a última reunião geral, no qual foram aprovadas a arte final, registro de Número Padrão Internacional de Livro (ISBN), reprodução e agendamento da divulgação a todas as crianças da comunidade. 
Os locais de aplicação da cartilha foram as escolas indígenas pelo fato de abranger o maior número de crianças, sendo que a estratégia educacional foi planejada e executada pelos pesquisadores e professores indígenas. Foram fornecidas cartilhas para todas as 118 crianças residentes nas aldeias do estudo, com adicional de 10\%, para as ausentes elou visitantes.

O estudo respeitou todos os aspectos éticos em pesquisa com seres humanos, em observância à Declaração de Helsinki e à Resolução 466/2012, tendo parecer favorável da Comissão Nacional de Ética em Pesquisa, CONEP n. 819.939/2014.

\section{RESULTADOS E DISCUSSÃO}

A cartilha para as crianças indígenas Haliti-Paresí sobre prevenção de hantavirose abordada neste estudo, é constituída de dezoito páginas, exceto capas, sendo nove páginas na língua portuguesa e o mesmo quantitativo na língua indígena Aruak e seus dialetos (Kozarini ou Waymarê). Todas as páginas são ilustradas, coloridas e compostas de narrativas e atividades participativas. Inicia-se o enredo em forma de narrativa, com um gênero discursivo universal e substancial no desenvolvimento da comunicação das crianças e concentra, na significação de experiências, atitudes, identidades, socialização de emoções e congêneres (Figura 1).

Figura 1 - Página 2 da cartilha educativa Haliti-Paresí em língua portuguesa.

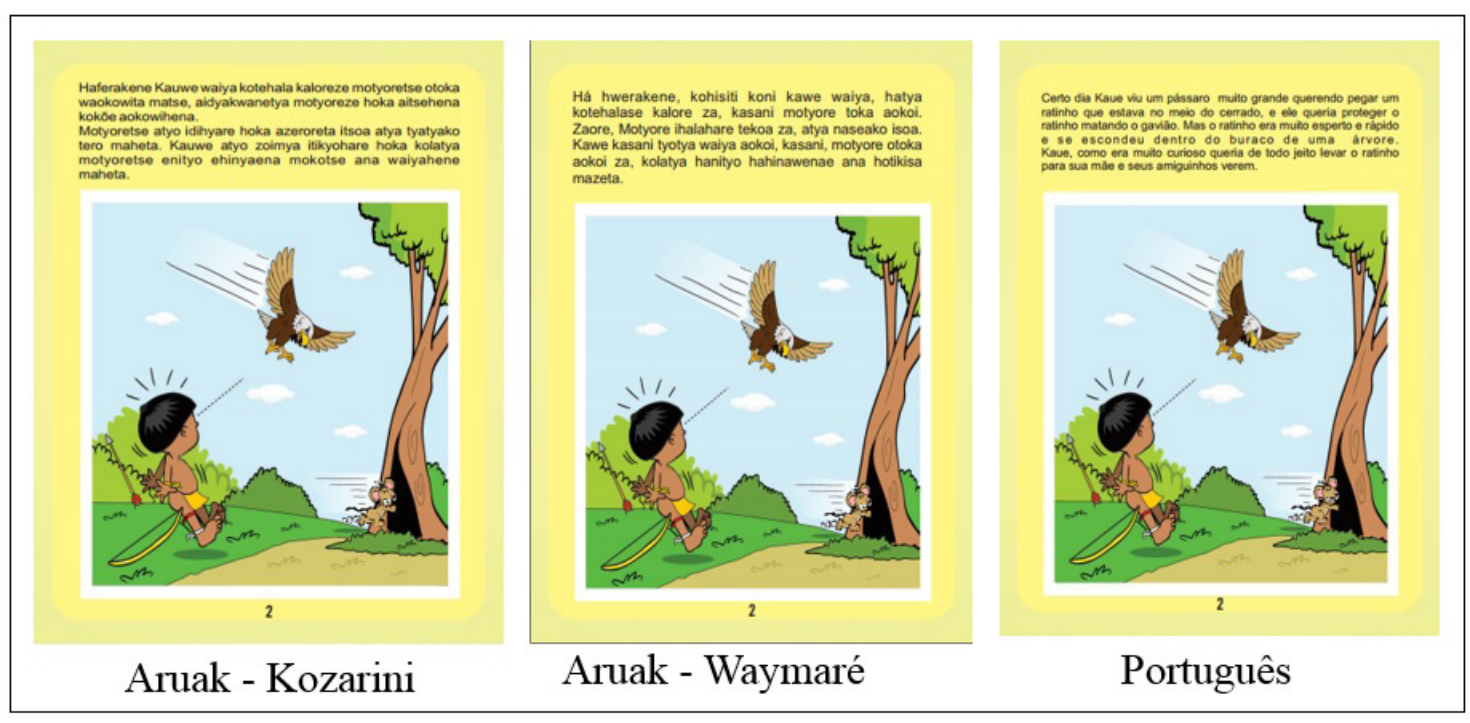

Fonte: Aruak Kozarini e Aruak Waymaré, 2016.

Ademais, a narrativa vai além da reprodução de histórias, constrói relações interpessoais, pois as crianças se apropriam de suas convenções para narrarem eventualidades nos distintos ambientes de socialização, como em suas casas. As crianças indígenas se integram na sociedade em que vivem, pelo fato de exercitarem as relações de poder, moralidade e demais aspectos da ordem social (OSTERMANN e SELL, 2015).

Além da estratégia pedagógica para ensino/aprendizado infantil do tipo narrativa, outros métodos aplicados neste estudo, embasados no lúdico, são comumente utilizados para esta finalidade, pois envolvem a didática como auxílio no processo de aprendizagem, conduzindo-os de modo significativo ao desenvolvimento da imaginação infantil (MARTINS, 2015). Esses métodos consistem em um processo ativo e interativo, onde se enquadram atividades dinâmicas e jogos educativos, contemplando experiências teórico-práticas (CRUZ et al, 2015), a fim de abordar conteúdos de maneira prazerosa, favorecendo sua assimilação. 
A figura 2 descreve um personagem com características físicas e ambientais semelhantes às crianças indígenas Haliti-Paresí, fazendo com que se sintam identificadas e envolvidas no enredo. O “Kaue” representa a criancice indígena que, como na realidade, passa maior parte do seu tempo brincando ao ar livre, envolvido em meio ao ambiente que vive. Além de serem representados o cotidiano na aldeia, os aspectos culturais e tradicionais marcantes foram ressaltados, como o arco e flecha, tanga e fitas, utilizados como adornos pelos indígenas dessa etnia (SILVEIRA, 2011).

Figura 2 - Página 1 da cartilha educativa Haliti-Paresí em língua portuguesa.

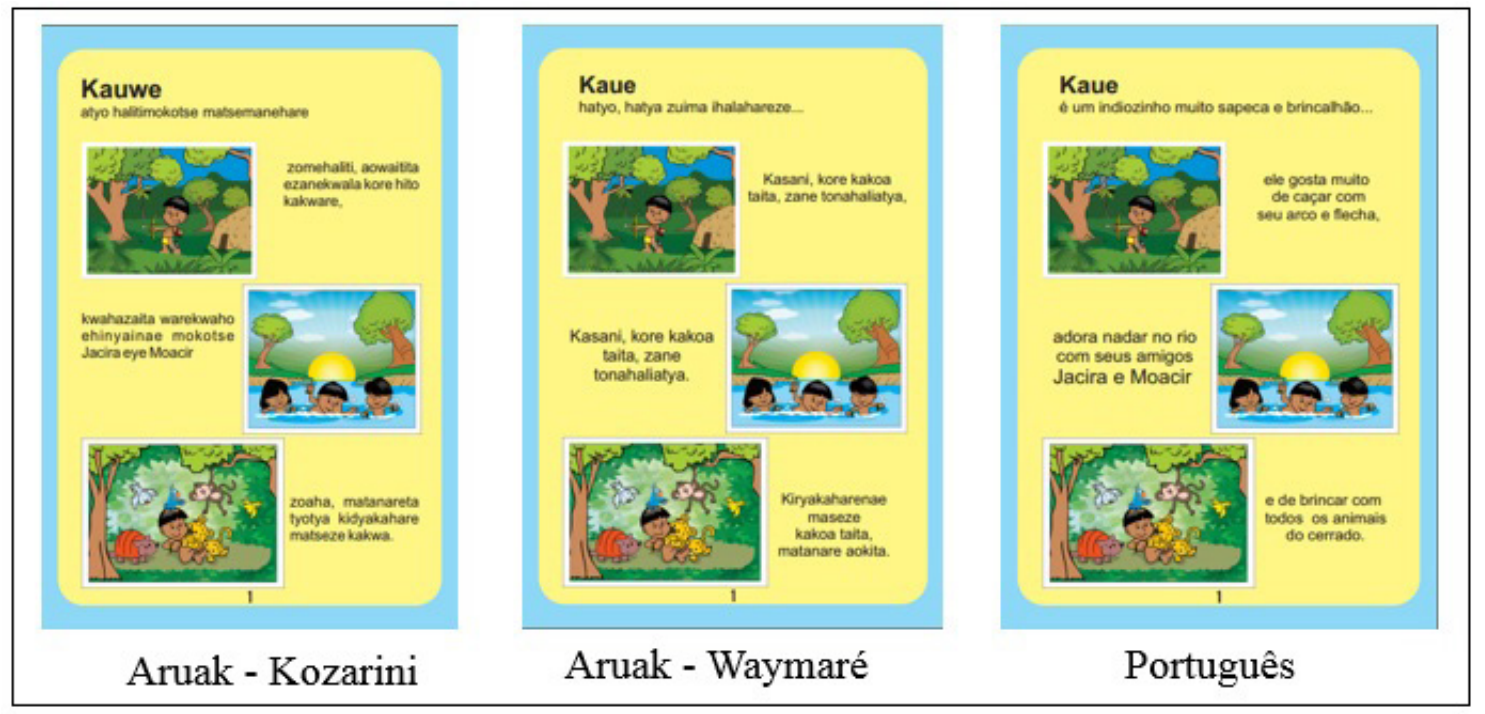

Fonte: Aruak Kozarini e Aruak Waymaré, 2016.

Na página posterior, inicia-se uma narrativa introdutória à hantavirose, em que atuam como personagens juntamente com o indígena, o roedor transmissor da doença e um de seus predadores, representado por um gavião (Figura 3).

Figura 3 - Página 6 da cartilha educativa Haliti-Paresí em língua portuguesa.

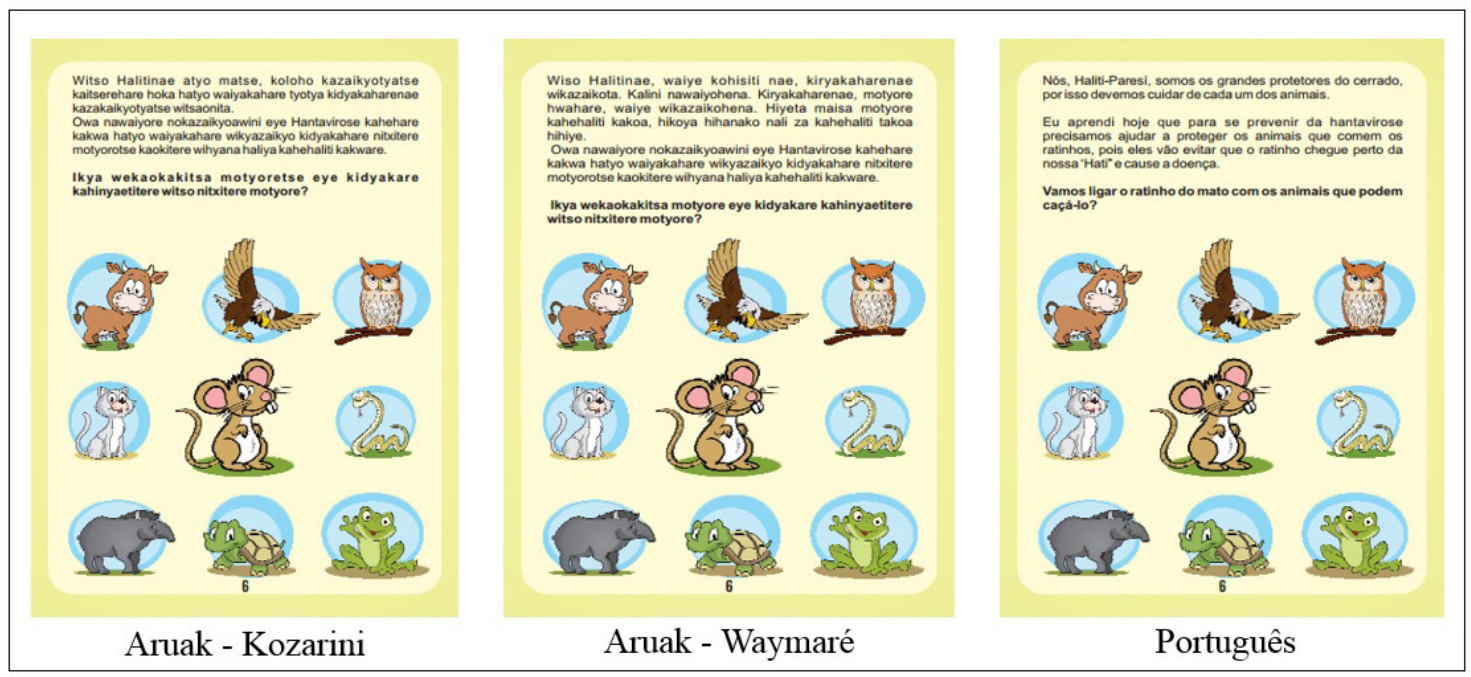

Fonte: Aruak Kozarini e Aruak Waymaré, 2016.

Os roedores silvestres são responsáveis pela transmissão da SPH pertencem à família Cricetidae, subfamília Sigmodontinae e Neotominae no Novo Mundo, e são os reservatórios dominantes do hantavírus (OLIVEIRA et al., 2014). 
Cada espécie de roedor reservatório possui um hantavírus específico, desse modo, a distribuição do hantavírus e consequentemente, da hantavirose, é determinada através da distribuição geográfica do hospedeiro (HJELLE e TORRES-PÉREZ, 2010).

Na região do médio norte mato-grossense, em localidades no entorno das aldeias Haliti-Paresí, foram identificados os roedores reservatórios Oligoryzomys utiairitensis e Calomys callidus, com os respectivos variantes virais: Castelo dos Sonhos e Laguna Negra. Ressalta-se que foram identificadas outras espécies de roedores silvestres no Mato Grosso, porém, ausentes de hantavírus (ROSA et al., 2012; TRAVASSOS et al., 2011).

Esses achados evidenciam a relevância de se instruir essa população, especialmente sua parcela mais vulnerável - as crianças por brincarem em áreas onde habitam os principais reservatórios do hantavírus. Deve-se enfatizar acerca dos riscos e perigos, prevendo e controlando consequências futuras, que implicam na suscetibilidade adjacente à essa comunidade (FERREIRA, 2011) em relação à infecção por hantavírus.

Além de sensibilizá-las quanto ao (re)conhecimento de dificuldades e colaborar com os órgãos competentes ao que se refere aos riscos que estão expostos, essa abordagem acabou refletindo no cotidiano dessas crianças e famílias, no modo de vida e vivencias ao mobilizar em relação às carências por eles enfrentadas em seu território, visando a promoção e ao desenvolvimento integral da saúde (AVELAR, 2013).

Dando seguimento à didática do material educativo, foi elaborada uma atividade interativa, onde, através da descrição do reservatório do vírus, há espaço para colorir, o que pode provocar/instigar a imaginação e interesse infantil ao integrar a criança como participante na história. Com essas atividades, há o estímulo do desenvolvimento cognitivo e facilitador da aprendizagem das crianças, ao ampliar suas capacidades de atenção, percepção, sensação, memória e demais elementos concernentes ao aprendizado (DIAS, 2013).

Neste contexto, a pintura a ser realizada na cartilha pela criança é uma arte que possibilita o desenvolvimento integral da criança, tanto motor, como afetiva e social (COSTA et al., 2010). Ao colorir o desenho do roedor reservatório da doença, a criança memoriza suas características com mais atenção, facilitando a associação entre as cores e o animal em uma possível visualização do mesmo em sua aldeia, remetendo à todas as orientações referentes à cautela para a prevenção da doença.

Nas páginas quatro e cinco, destaca-se a atuação da medicina ocidental, demonstrando a importância desta nas aldeias, o papel do curandeiro que atua nas "doenças de índio" e os profissionais de saúde que exercem sua profissão nessa localidade nas "doenças de não índio" (SILVEIRA, 2011). O mesmo autor destaca que o entendimento/aceitação dessa população quanto à necessidade da medicina dos “Imuti”, homens brancos, revelando avanço na implantação/fortalecimento e complementação da medicina ocidental associada à cultura dos Haliti-Paresí.

As ações de saúde em Atenção Básica na comunidade Haliti-Paresí são desenvolvidas pelo Distrito Sanitário Especial Indígena (DSEI) Cuiabá. O DSEI é a unidade gestora descentralizada do Subsistema de Atenção à Saúde Indígena criada a partir da consolidação da Lei Arouca em 1999, que em 2011, passou a ser gerido por meio de convênios firmados entre a Secretaria Especial de Saúde Indígena (SESAI) e a Sociedade Paulista para o Desenvolvimento da Medicina (SPDM) (ALTINI et al., 2013).

Assim, os profissionais como o médico, enfermeiro e odontólogo, denominadas de Equipes Multiprofissionais de Saúde Indígena (EMSI) que atuam nas aldeias, realizam suas atividades de assistência, promoção e prevenção no Polo Base que se localiza na aldeia Bacaval, além de cada aldeia contar com seu Agente Comunitário de Saúde Indígena (ACSI). O Polo Base Bacaval, local de atuação da equipe, é a primeira referência para os ACSI que atuam nas nove aldeias pertencentes a Campo Novo do Parecis e que integram esse estudo. 
Com o objetivo de aproximá-los da realidade de seu cotidiano para cuidados com a saúde, o material educativo também foi fornecido para a equipe do Polo Base e, sendo direcionado ao enfermeiro, por possuir maior vínculo com a comunidade (TERÇAS et al., 2016a) no desenvolvimento das ações relativas à educação em saúde.

O trabalho da enfermagem em relação ao processo de longitudinalidade na assistência à saúde indígena se pauta na oferta de assistência integral, em que o enfermeiro proporciona melhorias em seus cuidados de saúde e elabora um plano de ação eficiente, incluindo abordagens não convencionais, como a implementação da ludicidade, como meio de propiciar a reflexão e mudanças de práticas frente a necessidade de saúde. O profissional deve compreender sua atuação em uma perspectiva duradoura, a fim de que a continuidade da assistência, seja aprimorada e permanente (BARATIERI et al, 2012). Neste caso, cita-se a articulação entre o saber científico (equipe profissional) e o saber tradicional (pajés Haliti-Paresî), que possibilita uma escuta acolhedora, olhar ampliado do processo saúde-doença e fomento integral do cuidado (NEVES et al, 2013).

A seguir, foi enfatizada a preservação do ecossistema, em especial dos predadores do roedor transmissor do hantavírus, a fim de evitar a transmissão da infecção. Para isso, foi proposta uma atividade de associação, em a criança identifica os predadores do roedor existentes no seu meio (Figura 4).

A questão da preservação ambiental é marcante entre os indígenas, visto que a natureza é essencial para a manutenção do seu estilo de vida, o meio pelo qual eles obtêm grande parte da subsistência necessária para sua sobrevivência. Nesse aspecto, educador necessita envolver a comunidade com estratégias diferenciadas que abordem a questão ambiental, principalmente a preservação das matas e rios para garantia de água e destinação adequado do lixo, além de manter a fauna e flora como suporte à alimentação e sustentabilidade da comunidade (JÚNIOR, 2016).

Essas medidas ainda permitem o desenvolvimento de comportamentos e práticas éticas em relação à questão ambiental, em que o enfermeiro como educador adota métodos que propiciem efetiva participação, juntamente com a comunidade, na construção de novas relações com o mundo e promoção de inter-relações com a natureza, o que fortalece ainda mais o compromisso com o ecossistema (COSTA et al, 2013).

Essa população possui um zelo muito específico com sua casa (hati) e aldeia, no qual as mulheres estão constantemente lavando os utensílios, as roupas ou varrendo o chão de suas casas, auxiliadas pelas crianças (SILVEIRA, 2011). Ainda é descrita a questão do etnodesenvolvimento na comunidade Haliti-Paresí, uma vez que busca preservar sua cultura e o meio ambiente, no enfrentamento das pressões e avanços tecnológicos da cultura não indígena que os cercam. Assim, investem no turismo cultural, produção de artesanatos, educação indígena e parcerias para produção agrícola mecanizada sem, contudo, perder a autonomia e protagonismo enquanto povo.

Ao abranger essa população e demais públicos de culturas diversas em materiais educativos, devem ser superados alguns desafios quanto à sua elaboração, como a adequada representação de aspectos que remetem à sua realidade, construção em conjunto com os envolvidos em sua utilização, abrangendo peculiaridades culturais, com a valorização de hábitos tradicionais (PEREIRA, 1987).

A educação em saúde deve ser um instrumento de promoção do empoderamento, a fim de possibilitar um aprendizado que favoreça a autonomia do indivíduo e/ou coletividade na prevenção de agravos e enfrentamento de eventuais complicações (PEIXOTO, 2016).

Além disso, como forma de superar vulnerabilidades e desigualdades, é necessário compreender e intervir nos determinantes da saúde de uma população, esse campo deve preconizar a qualidade da informação acerca de certo problema, para que o indivíduo possa captá-la e incorporá-la em seu cotidiano, enfrentar barreiras culturais e expandir suas ações (ARAGÃO et al., 2015), a fim de se ter um maior grau de abrangência e consequentemente, inclusão social. 


\section{CONSIDERAÇÕES FINAIS}

O processo de elaboração da cartilha educativa promoveu a participativa e lúdica das crianças Haliti-Paresi, o (re)conhecimento do seu cotidiano e estabeleceu conexões entre exposição e risco e forma de prevenção da hantavirose. Os recursos como narrativas, perguntas, atividades interativas e ilustrações coloridas foram adotados como instrumentos permitiu ressignificação do saber científico ao articular as práticas cotidianas no seu espaço vivido, a percepção de vulnerabilidades e fortalecimento do uso da língua nativa.

A educação em saúde, especialmente no âmbito da enfermagem perpassa a comunicação informativa, e demandam recursos didáticos criativos para que o público alvo seja sensibilizado e estimulado a participar ativamente do processo ensino-aprendizagem. O lúdico e o brincar tem grande potencialidade, pois juntas podem influenciar na rotina e no cotidiano de vida da criança levando-a a despertar percepções que farão parte das ações que desenvolvem rotineiramente. A introdução de informações sobre hantavirose, adotou essa potencialidade no processo da construção da cartilha.

Cabe ressaltar, que o fato da cartilha estar grafada em português e Aruak (Waymaré e Kozarini), fortaleceu a língua nativa dos Paresí e assegurou a transmissão de informações de uma doença emergente em sua comunidade por meio de seu patrimônio linguístico, considerada como maior representação social desses povos. Esse entrelaçamento das representações sociais e vivências mostrou-se como importante estratégia na educação e oferta da assistência à saúde de forma mais integral e efetiva. Sugere-se que novas abordagens que assegurem o empoderamento, protagonismo e autonomia dessa comunidade sejam estimuladas e assim possam contribuir na prevenção desta e de outras doenças.

\section{REFERÊNCIAS}

ALTINI, E. et al. A Política de Atenção À Saúde Indígena no Brasil: breve recuperação histórica sobre a política de assistência à saúde nas comunidades indígenas. Conselho Indigenista Missionário: Brasília, 2013.

ARAGÃO, A.S. et al. Educação em saúde e enfrentamento de vulnerabilidades com adolescentes de programa social federal: um campo de fazer docente. In: III Congresso Internacional: trabalho docente e processos educativos. 2015.

AVELAR, P.M.S. A importância do lúdico no processo de ensino-aprendizagem na educação infantil. 93fl. Dissertação (Mestrado em Políticas Locais e Descentralização) - Universidade de Coimbra, 2013.

BARATIERI, T. et al. Longitudinalidade no trabalho do enfermeiro: relatos de experiência profissional. Rev Esc Enferm USP, v.46, n.5, p.1260-1267, 2012.

BASTA, P. C. et al. Perfil epidemiológico dos povos indígenas no Brasil: notas sobre agravos selecionados. In: Garnelo, L. (Org.). Saúde Indígena: uma introdução ao tema. Brasília: MEC-SECADI, 2012.

BERGER, S. Hantavirus Pulmonary Sindrome. Global status, 2016.

BRASIL. Ministério da Saúde. Casos confirmados de hantavirose 1993-2015, Brasília: 2016.

CASTRO, A.N.P; JÚNIOR, E.M.L. Desenvolvimento e validação de cartilha para pacientes vítimas de queimaduras. Rev. Bras. Queimaduras, v.13, n.2, p.103-113, ago.-set, 2014.

COSTA, G.M. et al. A importância do enfermeiro junto ao PSE nas ações de educação em saúde em uma escola municipal de Gurupi - TO. Revista Científica do ITPAC, v.6, n.2, p.1-12, 2013. 
COSTA, M.L.O. et al. Fazendo arte para aprender: A importância das artes visuais no ato educativo. Pedagogia em ação, v.2, n.2, p.95-104, 2010.

CRUZ, C.O. et al. Aplicação do programa de educação nutricional: sexta é dia de fruta? É sim senhor!. Revista Redes de Cuidados em Saúde, v.9, n.3, p.1-12, 2015.

DIAS, E. A importância do lúdico no processo de ensino-aprendizagem na educação infantil. Revista Educação e Linguagem, v.7, n.1, p.2-17, 2013.

FERNANDES, A.F. et al.. Construção e validação de cartilha educativa para alimentação saudável durante a gravidez. Rev Latino-Am. Enfermagem, v.22, n.4, p.611-620, 2014.

FERREIRA, F.B. O risco nas teorias sociológicas contemporâneas: Beck, Giddens e Luhmann. Raízes Jurídicas, v.7, n.2, p.135-144, 2011.

GOMES, A.L.Z; et al. O processo de construção de material educativo para a promoção da saúde da gestante. Rev Latino-Am. Enfermagem, v.20, n.1, p.1-8, 2012.

HJELLE, B; TORRES-PÉREZ, F. Hantaviruses in the Americas and Their Role as Emerging Pathogens. Viruses, v.2, n.12, p.2559-2586, 2010.

JÚNIOR, E.T. Práticas Integrativas e complementares em saúde, uma nova eficácia para o SUS. Estudos Avançados, v.30, n.86, p.99-112, 2016.

LEMOS, E.R.S; SILVA, M.V. Hantavírus. In: Coura, J.R.(Ed.). Dinâmica das doenças infecciosas e parasitárias. Rio de Janeiro: Guanabara Koogan, 2013.

MARTINS, L. O lúdico como estratégia pedagógica: uma análise no processo de ensino para o desenvolvimento cognitivo na educação infantil. 44fl. Trabalho de Conclusão de Curso (Graduação em Pedagogia) - Universidade Federal do Rio Grande do Norte, 2015.

NEVES, R.C.M; et al. A relação de intermedicalidade nos índios Truká, em Cabrobó - Pernambuco. Saúde Soc., v.22, n.2, p.566-574, 2013.

NICHIATA, L.Y.I. et al. Potencialidade do conceito de vulnerabilidade para a compreensão das doenças transmissíveis. Rev esc enferm USP, v.45, n.2, p.1769-1773, 2011.

OLIVEIRA, R.C. et al. Hantavirus reservoirs: current status with an emphasis on data from Brazil. Viruses, v. 6, n. 5, p. 1929-1973, 2014.

OSTERMANN, A.C; SELL, M.A. Construção da significação da experiência do abuso sexual infantil através da narrativa. D.E.L.T.A., v.31, n.2, p.307-322, 2015.

PEIXOTO, C.S. Análise da produção de material indígena didático para a escola kyikatêjê. 82 fl. Dissertação (Mestrado em Ciências da Educação) ESE Almeida Garret, 2016.

PEREIRA, A.H. O pensamento mítico do Paresi (Segunda parte). Pesquisas, Antropologia. São Leopoldo: Instituto Anchietano de Pesquisas, 1987.

ROSA, ES.T. et al. Molecular epidemiology of Laguna Negra Virus, Mato Grosso State, Brazil. Emerg Infect Dis, v.18, n.6, p.982-985, 2012.

SILVEIRA, E.M.S. Cultura como Desenvolvimento entre os Paresí Kozarini.157fl. Dissertação (Mestrado em Antropologia Social) Natal - UFRN, 2011. 
SIQUEIRA, H.C.H; ERDMANN, A.L. Construtivismo como método de pesquisa: possibilidade de geração de conhecimentos. Rev Enferm UERJ, v.15, n.2, p.291-297, abr.-jun. 2007.

TERÇAS, A.C.P. et al. Clinical research in indigenous lands: the experience with Haliti-Paresi. Rev enferm UFPE online, v.10, n.6, p.680-685, 2016a.

TERÇAS, ACP. et al. Os Haliti-Paresí: uma reflexão sobre saúde e demografia da população residente nas terras indígenas Paresí. Revista Espaço Ameríndio, v.10, n.1, p.226-253, 2016b.

TRAVASSOS, E.S. et al. Pygmy Rice Rat as Potential Host of Castelo dos Sonhos Hantavirus. Emerg Infect Dis, v.17, n.8, p.1527-1530, 2011.

VIAL, P.A. High-dose intravenous methylprednisolone for hantavirus cardiopulmonar syndrome in chile: a double-blind, randomized controlled clinical trial. Clin Infect Dis, v.57, n.7, p.943-951, 2013. 